\title{
A. Stalker: The One and Only Sam: A Story Explaining Idioms for Children with Asperger Syndrome and Other Communication Difficulties
}

\author{
Jessica Kingsley Publishers, Philadelphia, 2011, 64 pp, ISBN 978-1-84905-040-1, \\ $\$ 16.95$ (hardback)
}

Felicity Ruth Butterly

Published online: 29 October 2011

(C) Springer Science+Business Media, LLC 2011

\begin{abstract}
This book is the first that the reviewer has encountered that explains idioms in a way accessible to children with communication disorders. A 'how to' book on understanding idioms using cartoons and a step by step guide is a much needed resource for children with communication difficulties, their families, and professionals interested in holistically treating communication disorders.
\end{abstract}

This book gives examples, origins, and explanations of idioms. The author's central premise is that having these examples, origins, and explanations to hand will support communication in a child or young person with a communication disorder. More specifically, this book was designed for children with Asperger syndrome. The book emphasises on playing to the abilities in communication disorders like Aspergers, such as attention to construction and in this case the construction (and deconstruction) of language, using relevant and accessible language.

The book starts with a very useful 'how to use this book' section and sticks to the 'how to' strategy. There is a stepby-step guide on how to process idioms like 'it's raining cats and dogs'. Descriptions of a young boy called 'Sam' finding idioms in his everyday life confusing, but having them deconstructed by his parents, are combined with cartoons of Sam as the hero of various idiom scenarios. The book finishes with a reference section explaining additional idioms, and recommendations for other books and websites.

One gets the feeling that the author, Aileen Stalker, an Occupational Therapist working with children with a wide variety of disorders (according to the book jacket), uses specific case material to break down the purpose of an idiom to a child with a communication disorder. The emphasis the author places on deconstructing language into units of meaning and then reconstructing those units into real life scenes, both verbally and pictorially, is admirable and practical. A complicated concept like idioms are not necessary for good communication, one might think, until, as Sam does in the book, one comes across them in everyday conversation. The intentions behind this book are therefore very grounded making it potentially very useful for children with communication disorders, their families and early intervention professionals.
F. R. Butterly $(\bowtie)$

Faculty of Health and Life Sciences, Coventry University,

Coventry, UK

e-mail: butterlf@uni.coventry.ac.uk

F. R. Butterly

Charles Ward Building, Room CWB20, Coventry CV1 5FB, UK 